\title{
Monitoring enzyme replacement treatment in exocrine pancreatic insufficiency using the cholesteryl octanoate breath test
}

\author{
S Mundlos, P Kühnelt, G Adler
}

\begin{abstract}
The cholesteryl- ${ }^{-14} \mathrm{C}$-octanoate breath test was used to monitor the intraluminal enzymatic activity of pancreatin preparations in six patients with severe pancreatic insufficiency. Conventional enzyme replacement, with cimetidine as an adjunct, was compared to supplementation with enteric coated microspheres. In healthy control subjects, ${ }^{14} \mathrm{CO}_{2}$ excretion rose rapidly and peaked at 90-120 minutes; mean (SD) cumulative recovery at four hours was $51(8) \%$. In patients with pancreatic insufficiency on no treatment mean (SD) cumulative recovery was only $6(4) \%$. After pancreatin, with previous administration of cimetidine, it increased to 27 (11)\% with a time course resembling that in controls. With $2 \mathrm{~mm}$ enteric coated microspheres, ${ }^{14} \mathrm{CO}_{2}$ excretion did not rise significantly before 120 minutes and cumulative recovery after four hours was $15(11) \%$. In a control study, $2 \mathrm{~mm}$ radio-opaque microspheres did not empty from the stomach until two hours after ingestion. The results suggest that the cholesteryl octanoate breath test can be successfully used to monitor the intraluminal enzymatic activity after treatment with different forms of enzyme replacement in pancreatic insufficiency. In contrast to treatment with conventional pancreatin and cimetidine as an adjunct, $2 \mathrm{~mm}$ enteric coated microspheres did not show in vivo enzymatic activity until two hours after administration.
\end{abstract}

Medical treatment of steatorrhoea in pancreatic exocrine insufficiency is based on oral administration of porcine pancreatic enzymes. Despite large doses of pancreatin, persistent steatorrhoea is common. This has been attributed to the fragile characteristics of lipase and other pancreatic esterases which are irreversibly inactivated below $\mathrm{pH} 4$. $^{1}$ Efforts have therefore been made to improve the efficacy of treatment by protecting the enzyme's activity from acidic inactivation by the use of cimetidine and $\mathrm{pH}$ sensitive enteric coating. The latter maintains enzyme integrity at low $\mathrm{pH}$ but liberates the contained pancreatin as the $\mathrm{pH}$ increases above $5 \cdot 5$. In the commercially available enteric coated preparations (Kreon, Panzytrat in Europe; Pancrease, Cotazym-S in the United States), pancreatin is formulated into microspheres ranging from $1 \mathrm{~mm}$ to $2.8 \mathrm{~mm}$ in diameter. ${ }^{2}$

The effectiveness of pancreatic enzyme replacement is commonly assessed by measuring the reduction in the degree of steatorrhoea ${ }^{34}$ or the duodenal recovery of enzyme activity after oral administration. ${ }^{56}$ Clinical trials comparing adjunctive cimetidine with enteric coated microspheres have given conflicting results due to difficulties in measuring the clinical efficacy of enzyme substitution. Enteric coated microspheres were found to be superior to cimetidine as an adjunct to conventional (uncoated) enzyme supplementation, ${ }^{478}$ or vice versa ${ }^{569}$ or of equal efficiency. ${ }^{3}$

Recently, a new breath test with cholesteryl${ }^{14} \mathrm{C}$-octanoate as the substrate has been successfully used to diagnose pancreatic insufficiency in rats ${ }^{10}$ and humans. ${ }^{11}$ The test is based on the intraluminal hydrolysis of cholesteryl $-{ }^{14} \mathrm{C}$ octanoate by pancreatic cholesterol esterase and the subsequent absorption and rapid metabolism of ${ }^{14} \mathrm{C}$-octanoic acid to ${ }^{14} \mathrm{CO}_{2}$. Measurement of ${ }^{14} \mathrm{CO}_{2}$ in breath allows an indirect estimation of intraluminal hydrolytic activity and its time course. Only pancreas specific enzyme activity is measured since intraluminal activity of cholesterol esterase is of pancreatic origin. ${ }^{12}$

In this study, the cholesteryl octanoate breath test was used to monitor the release and activity of cholesterol esterase from different preparations of pancreatin in patients with severe pancreatic exocrine insufficiency. We compared treatment with acid resistant enteric coated microspheres (Panzytrat 20.000, Nordmark, FRG) to treatment with identical uncoated enzyme supplements with and without adjunctive cimetidine.

\section{Methods}

\section{SUBJECTS}

Eleven healthy volunteers without a history of pancreatic, pulmonary, or hepatic disease served as controls for the breath test with cholesteryl${ }^{14} \mathrm{C}$-octanoate. Of these, five subjects were also tested with ${ }^{14} \mathrm{C}$-octanoic acid. In addition, gastric emptying of $2 \mathrm{~mm}$ microspheres was studied in five healthy volunteers. We studied six patients with severe exocrine pancreatic insufficiency but no hepatic or respiratory disease. All patients had steatorrhoea with a fat excretion of $8-46 \mathrm{~g}$ per day, an abnormal para-aminobenzoic acid (PABA) test (less than $40 \%$ PABA recovery in urine over six hours), and decreased chymotrypsin activity (less than $4 \mathrm{U} / \mathrm{g}$ ) in stools. In patients 1 to 4 a secretin-cholecystokinin test was performed and showed intraduodenal lipase activity ranging from $0 \cdot 24 \%$ to $7 \cdot 24 \%$ of control values. The study protocol was approved by the ethics committee of the University of Marburg. 
TEST MEAL AND BREATH COLLECTION

Cholesteryl octanoate and octanoic acid were obtained from Sigma, München, FRG. The substrate, cholesteryl $-{ }^{1+} \mathrm{C}$-octanoate, was kindly provided by Dr Gantz, Hoechst AG, Frankfurt. The material was $99 \%$ pure by thin layer chromatography zonal scanning and had a specific activity of $20 \cdot 7 \mathrm{mCi} / \mathrm{g}$. ${ }^{14} \mathrm{C}$-octanoic acid was obtained from Amersham, Braunschweig, FRG. The substrate was administered in a 300 $\mathrm{ml}$ liquid test meal. For preparation of the test meal, cholesteryl octanoate $(1 \cdot 5 \mathrm{~g})$ was dissolved in $20 \mathrm{ml}$ cholesterol free triglyceride at $90^{\circ} \mathrm{C}$. Cholesteryl- ${ }^{14} \mathrm{C}$-octanoate $(4 \mu \mathrm{Ci})$ in heptane was then added. For emulsification of the substrate, $3 \mathrm{ml}$ glycerol (Merck) and $5 \mathrm{~g}$ lecithin (Epikuron 170, Lucas-Meyer, Hamburg, FRG) was dissolved in $300 \mathrm{ml}$ of water. The oil was then added by drops to the aqueous phase and emulsified by stirring with a high speed Ultra-Turrax for 10 minutes. For the study with ${ }^{14} \mathrm{C}$-octanoic acid, the emulsion was prepared in an identical way using equimolar amounts of cholesterol, octanoic acid, and ${ }^{14} \mathrm{C}$-octanoic acid.

All subjects were studied after a 12 hour overnight fast. Patients with pancreatic disease stopped their enzyme supplementation three days before the test. A fasting breath sample was obtained and the test meal was then drunk over a five minute period. A $1 \mathrm{mmol}$ sample of expired $\mathrm{CO}_{2}$ was collected every 15 minutes for four hours as described elsewhere. ${ }^{10}$ It was assumed that patients and control subjects expired $9 \mathrm{mmol} \mathrm{CO} 2 / \mathrm{kg} / \mathrm{h}$ and that expiration was linear at each 15 minute interval. Cumulative ${ }^{14} \mathrm{CO}_{2}$ recovery was determined by summation of the calculated ${ }^{14} \mathrm{CO}_{2}$ expired for each 15 minute period.

The healthy control subjects had two breath tests (ester and hydrolysate) on no treatment. The patients performed the following breath tests with ester in random order: (a) no treatment $(n=6)$; (b) enteric coated microspheres $(n=6)$; (c) unprotected pancreatin (crushed microspheres) plus $400 \mathrm{mg}$ cimetidine $(\mathrm{n}=5)$; (d) unprotected pancreatin without cimetidine $(\mathrm{n}=2)$.

All enzyme substitution was carried out with Panzytrat 20.000 (Nordmark, FRG). This preparation contains 50 enteric coated $\mathrm{pH}$ sensitive microspheres of $2 \mathrm{~mm}$ diameter with an activity of $20000 \mathrm{U}$ lipase, $18000 \mathrm{U}$ amylase, and 1000 U protease per capsule (manufacturer's data). Each patient took five capsules with the test meal. For unprotected pancreatin, the contents of five capsules were crushed and suspended in the test meal immediately before administration. The cimetidine was taken 30 minutes before drinking the test meal. ${ }^{13}$

\section{GASTRIC EMPTYING}

Gastric emptying of microspheres was studied in five healthy volunteers using $2 \mathrm{~mm}$ radio-opaque plastic beads. ${ }^{14}$ Each subject took 20 beads, which were administered in pancreatin capsules by replacing four of the 50 microspheres in each of the five capsules. These were then given with the non-radioactive test meal. $25 \mathrm{~g}$ of xylose was added to the test meal to assess simultaneously the emptying of the meal. After administration, $x$ rays of the abdomen were obtained hourly for four hours and blood samples were collected every 30 minutes for xylose measurements.

\section{ANALYTICAL PROCEDURES}

The in vitro release of lipase and cholesterol esterase activity from the enteric coated microspheres (Panzytrat 20.000) was studied by incubation in phosphate buffered saline $(25.7$ $\left.\mathrm{mmol} \mathrm{Na}_{2} \mathrm{HPO}_{4}, 34 \cdot 2 \mathrm{mmol} \mathrm{NaCl}\right)$ at $\mathrm{pH} 6$ with agitation, as described by Düdder and Spener. ${ }^{15}$ Lipase activity was measured as described by Ziegenhorn et $a l,{ }^{16}$ and cholesterol esterase activity according to Tarbutton and Gunter ${ }^{17}$ using cholesteryl octanoate as the substrate. Activity of cholesterol esterase was expressed as units/l with 1 unit hydrolysing $2.6 \mu \mathrm{mol}$ of substrate per minute.

Xylose in serum was determined using the bromoaniline method. ${ }^{18}$

\section{STATISTICAL ANALYSIS}

Statistical analysis was performed using the Kruskal-Wallis test. Values are expressed as means (SD).

\section{Results}

\section{CONTROL SUBJECTS}

Figure 1 shows ${ }^{14} \mathrm{CO}_{2}$ recovery over 240 minutes after administration of the test meal containing cholesteryl- ${ }^{14} \mathrm{C}$-octanoate, expressed as per cent of dose administered. The appearance of ${ }^{14} \mathrm{CO}_{2}$ in breath was rapid, leading to a steep increase over the first 60 minutes and then continuing at a more constant rate for another 120 minutes before it slowly declined. There was no well defined peak.

A similar recovery and time course was seen after administration of the test meal with hydrolysed substrate $\left({ }^{14} \mathrm{C}\right.$-octanoate and cholesterol) (Fig 1). This indicates that ester hydrolysis was not rate limiting in control subjects.

The values for cumulative recovery are summarised in Figure 2.

\section{PATIENTS}

Without enzyme supplementation, ${ }^{14} \mathrm{CO}_{2}$ recovery was markedly reduced throughout the

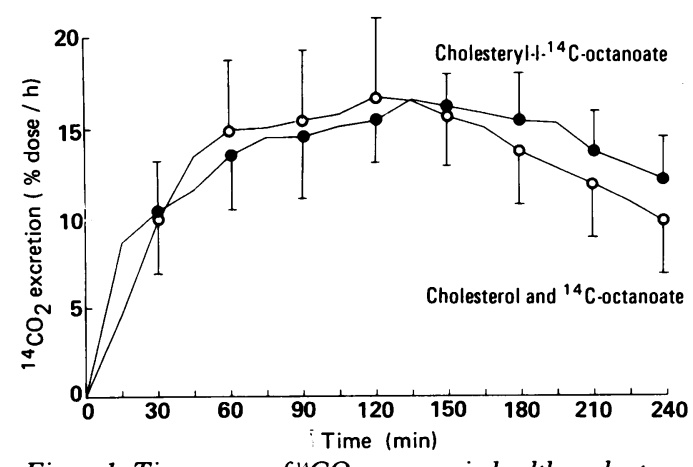

Figure 1: Time course of ${ }^{14} \mathrm{CO}_{2}$ recovery in healthy volunteers after ingestion of the test meal containing cholesteryl $-1-{ }^{14} \mathrm{C}-$ octanoate $\mathrm{v}$ the test meal containing cholesterol and ${ }^{14} \mathrm{C}$ octanoate (mean $(S D))$. 
$120 \mathrm{~min}$

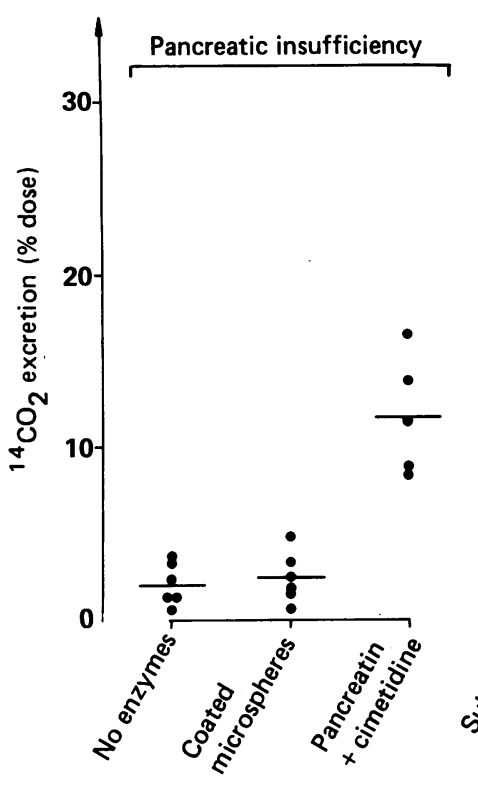

$240 \mathrm{~min}$

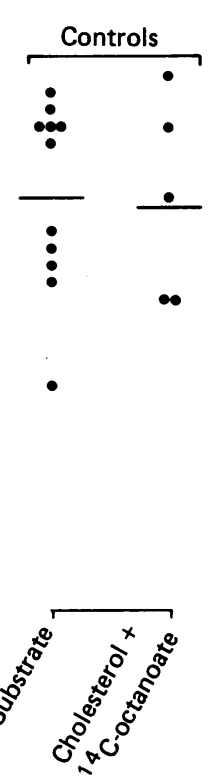

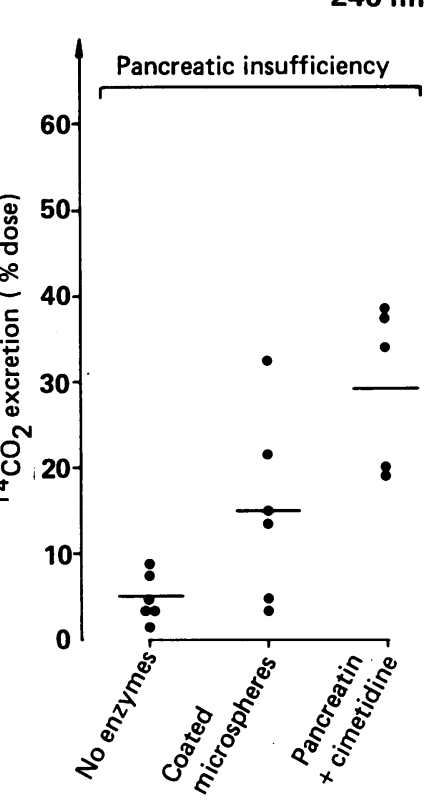
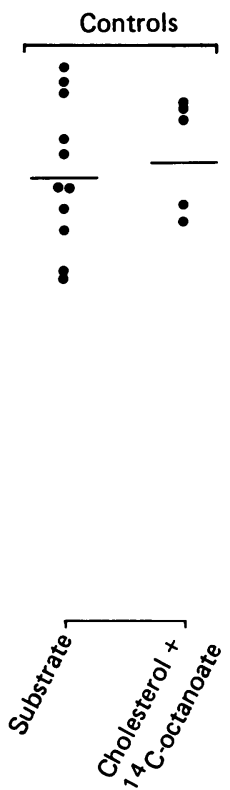

Figure 2: Cumulative ${ }^{14} \mathrm{CO}_{2}$ recovery 120 min and 240 minutes after ingestion of the test meal.

240 minutes of the study in all patients (Fig 3A). The enteric coated microspheres had a different effect on ${ }^{14} \mathrm{CO}_{2}$ recovery in each patient (Fig 3B). Two patients ( 3 and 6 ) showed no increase, whereas patients $1,2,4$, and 5 showed a sudden increase in ${ }^{14} \mathrm{CO}_{2}$ excretion between 120 and 180 minutes. Only in patient 4 did this increase, however, lead to control values at this time. Cumulative recovery at 120 minutes was no
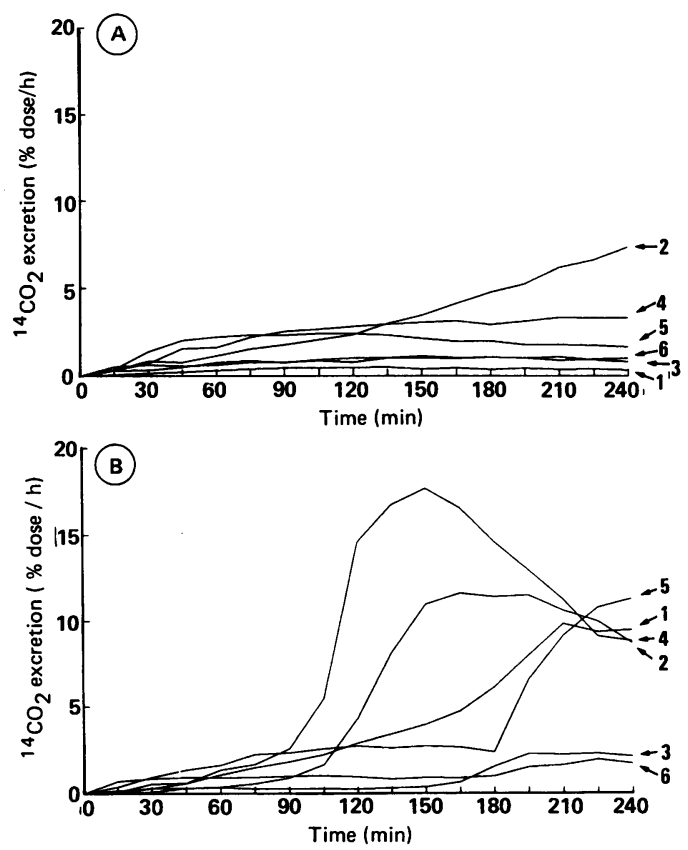

Figure 3: Time course of ${ }^{14} \mathrm{CO}_{2}$ recovery in patients (numbers) with pancreatic insufficiency after ingestion of the test meal containing cholesteryl- $-^{14} \mathrm{C}$-octanoate without enzyme substitution $(A)$, after enzyme substitution with enteric coated microspheres $(B)$, and after substitution with pancreatin and previous administration of cimetidin (C).

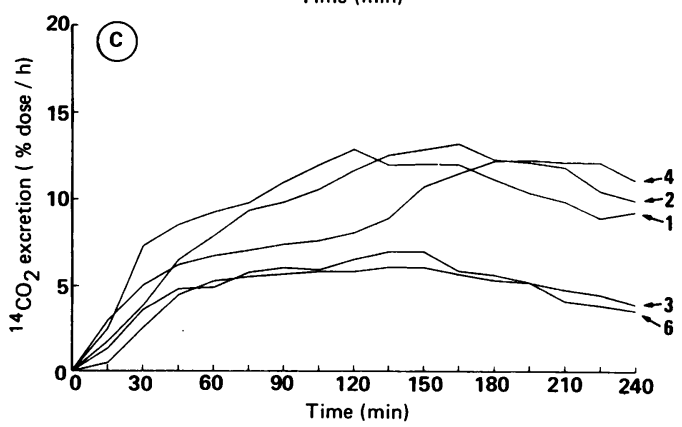

greater than without enzyme substitution (Fig 2). Even though most patients showed an increase thereafter, the 240 minute cumulative recovery did not reach control values and was not statistically different from recovery without enzyme substitution (Fig 2).

Uncoated pancreatin and cimetidine produced a time course of ${ }^{14} \mathrm{CO}_{2}$ recovery in patients comparable to that in control subjects (Fig 3C). The 120 and 240 minute cumulative recovery was significantly higher $(\mathrm{p}<0.01)$ than without enzyme substitution (Fig 2). The ${ }^{14} \mathrm{CO}_{2}$ recovery in each patient was always higher with treatment with pancreatin plus cimetidine than with enteric coated microspheres. The two patients who received uncoated pancreatin without cimetidine showed an initial rise in ${ }^{1+} \mathrm{CO}_{2}$ excretion comparable to the test meal with cimetidine, but this was followed by a rapid decline leading to much lower cumulative recoveries at 240 minutes ( $19 \%$ in patient $1,14 \%$ in patient 2 , not shown).

RELEASE OF ENZYME ACTIVITY IN VITRO

Figure 4 shows the release of lipase and cholesterol esterase activity from enteric coated

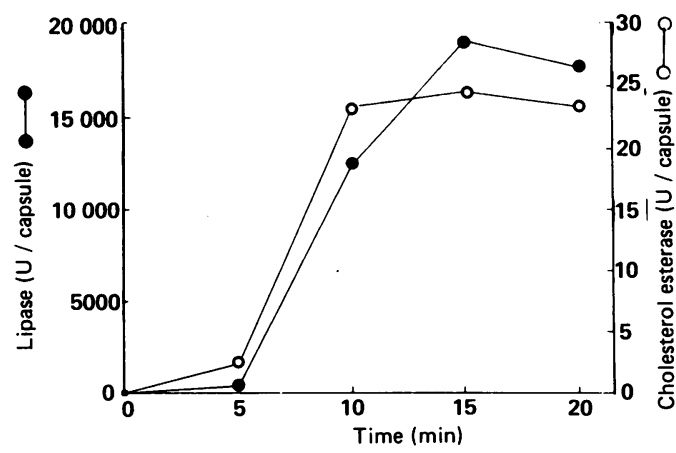

Figure 4: Release of activity of lipase and cholesterol esterase from enteric coated microspheres contained in one capsule during incubation in phosphate buffer at pH 6; mean of 10 measurements. 
Figure 5: Time course of gastric emptying of $2 \mathrm{~mm}$ microspheres in five healthy volunteers expressed as per cent microspheres emptied from stomach. Gastric emptying of the test meal was monitored by measurement of xylose recovery in blood $($ mean $(S D))$.

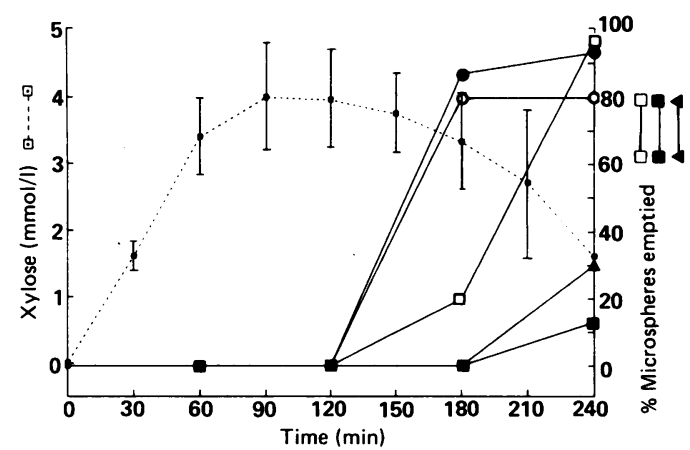

microspheres during incubation in phosphate buffer at $\mathrm{pH} 6$. Both enzymes were released rapidly and simultaneously, their activities peaking at 15 minutes. The maximum activity was 19500 units per capsule for lipase and 23 units per capsule for cholesterol esterase. The activity of lipase is in agreement with the manufacturer's data.

\section{GASTRIC EMPTYING OF 2 MM MICROSPHERES}

Figure 5 shows the time course of gastric emptying of $2 \mathrm{~mm}$ radio-opaque microspheres in healthy control subjects. The rapid increase of xylose concentration in blood indicates that gastric emptying of the test meal was not delayed. In all five subjects studied gastric emptying of the $2 \mathrm{~mm}$ microspheres did not begin until two hours after ingestion of the test meal. This resembles the time course of ${ }^{14} \mathrm{CO}_{2}$ excretion after enzyme supplementation with enteric coated microspheres in patients with pancreatic insufficiency (Fig 3B).

\section{Discussion}

This study clearly suggests that the cholesteryl octanoate breath test is of value in the indirect assessment of the intraluminal enzymatic activity of cholesterol esterase from orally administered pancreatic enzymes in patients with exocrine pancreatic insufficiency. Enteric coated microspheres of $2 \mathrm{~mm}$ diameter did not show enzymatic activity until two hours after ingestion. Studies in healthy control subjects suggested that this delay was due to a selective retention of spheres in the stomach.

As pointed out by Cole et al," cholesteryl octanoate is a very hydrophobic molecule and might therefore be located predominantly in the core of the emulsified triglyceride droplets. Accordingly, its hydrolysis is likely to require the concerted action of lipase, phospholipase, and cholesterol esterase. ${ }^{19}$ Since cholesterol esterase requires bile salts to be present at micellar concentration for full enzyme activity, ${ }^{19}$ no digestion of substrate will take place before the test meal has reached the duodenum and sufficient emulsification has taken place. When liberated, octanoate is rapidly absorbed, transported without prior esterification via the portal vein to the liver, and oxidised to ${ }^{14} \mathrm{CO}_{2} \cdot{ }^{2021}$ No difference was observed in the time course and cumulative recovery of ${ }^{14} \mathrm{CO}_{2}$ after administration of cholesteryl- ${ }^{14} \mathrm{C}$-octanoate compared to ${ }^{14} \mathrm{C}$-octanoate. This indicates that hydrolysis of the substrate was not rate limiting in control subjects.

All patients with pancreatic insufficiency had a very low ${ }^{14} \mathrm{CO}_{2}$ output after administration of the test meal containing cholesteryl octanoate. This was only partially restored when powdered pancreatin was given with cimetidine. Then, the time course resembled the control curve, indicating that the enzyme was released at the same rate as it was secreted in control subjects but was present in insufficient concentration or activity. With a similar substrate, Cole et al found ${ }^{14} \mathrm{CO}_{2}$ recovery after pancreatin administration to approach control values. " Our failure to achieve such correction might be explained by a lower activity of cholesterol esterase in the enzyme preparation we used.

Earlier studies have described a significant reduction of steatorrhoea with adjunct cimetidine. ${ }^{62}$ Cimetidine is believed to improve the efficacy of pancreatin in two ways. ${ }^{132}$ Firstly, it raises gastric $\mathrm{pH}$ above 4 , protecting the enzymes from acidic degradation. In addition, the increased duodenal $\mathrm{pH}$ prevents precipitation of glycine conjugated bile salts which are necessary for lipase and cholesterol esterase activity and micellar solubilisation. Secondly, it reduces the volume of gastric secretion, thus increasing enzyme concentration in the duodenum. Our results support the proposed effects of cimetidine. Without previous administration of cimetidine, cumulative recovery was reduced to $50 \%$ compared to that after treatment with cimetidine.

Administration of enteric coated microspheres resulted in a delayed rise in ${ }^{14} \mathrm{CO}_{2}$ recovery in four patients and no rise in two patients. The cumulative recovery at 240 minutes seemed higher than with no treatment, but was not statistically significant.

A recent study by Meyer $e t$ al suggested that only particles smaller than $1.4 \mathrm{~mm}$ pass through the pylorus simultaneously with food. ${ }^{2}$ The delayed effect of the microspheres in our study may therefore be due to retention of spheres in the stomach until most of the liquid test meal had been emptied, as suggested by our subsidiary study with radio-opaque $2 \mathrm{~mm}$ spheres. Therefore, the size of the pancreatin microspheres is the most likely cause of their limited efficacy. ${ }^{5}$ Even though our test meal obviously does not have the characteristics of a normal meal in terms of the content of liquid and solid particles, we believe that the results can be extrapolated. It has been proposed by many workers that once solids have been reduced to a size small enough to pass through the pylorus, both the liquids and solids will be emptied in the same rate. ${ }^{142} 25$ Accordingly, no difference is to be expected in the effectiveness of enzyme supplementation with microspheres with regard to the composition of the meal if the sphere size is larger than the particle size carried simultaneously with food.

Provided that the duodenal $\mathrm{pH}$ is above 6 , the delayed rise in ${ }^{14} \mathrm{CO}_{2}$ seems not to be caused by a slow release of enzyme activity from the microspheres since in vitro experiments showed a rapid dissolution of microspheres at $\mathrm{pH} 6$ with peak activity of lipase and cholesterol esterase within 15 minutes. In patients with severe pan- 
creatic insufficiency, however, duodenal $\mathrm{pH}$ is known to be low. ${ }^{1692326}$ In the late postprandial period - that is, 120 to 180 minutes after a meal duodenal $\mathrm{pH}$ may decrease to less than 4 . Under these circumstances pancreatin will not be liberated from its enteric coat until the spheres have reached distal areas of the small bowel with a more alkaline $\mathrm{pH}$. In a recent study, Guarna $e t$ al reported that there was higher enzyme activity in the ileum than in the duodenum in patients with pancreatic insufficiency taking enzyme replacement treatment. ${ }^{26}$

Many problems have to be solved before a sufficient form of enzyme substitution in patients with pancreatic insufficiency is established. In the present study the cholesteryl octanoate breath test was not used to analyse the overall efficacy of pancreatin supplementation in patients with pancreatic insufficiency. This test, however, offers the unique possibility of monitoring the in vivo release of enzymatic activity and comparison of different forms of enzyme preparations.

We thank C Beglinger, University of Basel, Department of Medicine, for the preparation of radio-opaque microspheres.

1 Di Magno EP, Malagelada JR, Go VLW, Moertel CG. Fate of orally ingested enzymes in pancreatic insufficiency. Comparison of two dosage schedules. $N$ Engl $7 \mathrm{Med} 1977$ 296: 1318-22.

2 Meyer JH, Elashoff J, Porter-Fink V, Dressman J, Amidon GL. Human postprandial gastric emptying of $1-3$ millimeter spheres. Gastroenterology 1988; 94: 1315-25.

3 Lankisch PG, Lembcke B, Göke B, Creutzfeld W. Therapy of pancreatigenic steatorrhea: Does acid protection of panpancreatigenic steatorrhea: Does acid protection of pan24: 753-7.

4 Graham DY. An enteric coated pancreatic enzyme preparation that works. Dig Dis Sci 1979; 24: 906-9.

5 Dutta SK, Rubin J, Harvey J. Comparative evaluation of the therapeutic efficacy of a $\mathrm{pH}$-sensitive enteric coated pancreatic enzyme therapy in the treatment of exocrine pancreatic insufficiency. Gastroenterology 1983; 84: 476-82.

6 Regan PT, Malagelada JR, DiMagno EP, Glanzman SL, Liang V, Go W. Comparative effects of antacids, cimetidine and enteric coating on the therapeutic response to oral enzymes in severe pancreatic insufficiency. $N$ Engl $f$ Med 1977; 297: 854-8.
7 Stead RJ, Skypala I, Hodson ME. Treatment of steatorrhea in cystic fibrosis: a comparison of enteric coated microsphere of pancreatin versus non-enteric coated pancreatin and adjuvant cimetidine. Aliment Pharmacol Therap 1988; 2 471-82.

8 Dutta SK, Hubbard S, Appler M. Critical examination of therapeutic efficacy of a pH-sensitive enteric-coated pancreatic enzyme preparation in treatment of exocrine pancreatic insufficiency secondary to cystic fibrosis. Dig Dis Sci 1988; 33: 1237-44.

9 Marrotta F, O'Keefe SJD, Marks IN, Girdwood A, Young G. Pancreatic enzyme replacement therapy. Dig Dis Sci 1989 34: 456-61.

10 Mundlos $S$, Rhodes JB, Hofmann AF. The cholestery octanoate breath test: a new procedure for detection of pancreatic insufficiency in the rat. Pediatr Res 1987; 22: 257 61.

11 Cole SG, Rossi S, Stern A, Hofmann AF. Cholesteryl octanoate breath test. Preliminary studies on a new noninvasive test of human pancreatic exocrine function. Gastroenterology 1987; 93: 1372-80.

12 Gallo LL, Chiang Y, Vahouny GV, Treadwell CR. Localization and origin of rat intestinal cholesterol esterase determined by immunocytochemistry. $\mathcal{F}$ Lipid Res 1980 ; 21 : determined 45 .

13 Regan PT, Malagelada JR, DiMagno EP, Go VLW. Rationale for the use of cimetidine in pancreatic insufficiency. Mayo Clin Proc 1978; 53: 79-83.

14 Smith HJ, Feldman M. Influence of food and marker length on gastric emptying of indigestible radiopaque markers in healthy humans. Gastroenterology 1986; 91: 1452-5.

15 Düdder $M$, Spener $F$. Vergleich der Lipaseaktivität in Pankreatin-Fertigarzneien. Pharmazentische Zeitschrift $1988 ; 42: 56-66$.

16 Ziegenhorn J, Neumann U, Knitsch KW, Zwez W. Determination of serum lipase. Clin Chem 1979; 25: 1067.

17 Tarbutton PN, Gunter CR. Enzymatic determination of total cholesterol in serum. Clin Chem 1974; 20:724-5.

18 Miller B. Der D-Xylose-Test. In: Engelhardt A, Lommel H, eds. Malabsorption maldigestion. Weinheim: Verlag Chemie, eds. Malabsorpti

19 Rudd EA, Brockman HL. Pancreatic carboxyl ester lipase (cholesterol esterase). In: Borgstrom B, Brockman HL, eds Lipases. New York: Elsevier, 1984: 185-204.

20 Greenberger NJ, Skillman TG. Medium-chain triglycerides. Physiologic considerations and clinical implications. $N$ Engl f Med 1969; 280: 1045-58.

21 Schwabe AD, Bennet LR, Bowman LP. Octanoic acid absorption and oxidation in humans. $f$ Appl Physiol 1964; 19: 335-7.

22 Cox FL, Isenberg JW, Asher AP, Douley RR. The effect of cimetidine on maldigestion in cystic fibrosis. $\mathcal{F}$ Pediatr 1979 99: 448

23 Zentler-Munro PL, Fine DR, Batten JC, Northfield TC Effect of cimetidine on enzyme inactivation, bile acid precipitation, and lipid solubilisation in pancreatic steatorrhoea due to cystic fibrosis. Gut 1985; 26: 892-901

24 Meyer JH, Ohashi H, Jehn D, Thompson JB. Size of live particles emptied from the human stomach. Gastroenterology 1981; 80: 1489-96.

25 Siegel JA, Urbain JL, Adler LP, et al. Biphasic nature of gastric emptying. Gut 1988; 29: 85-9.

26 Guarna L, Rodriguez R, Malagelada JR. Ileal vs duodenal enzyme activities in treated and untreated pancreatic steatorrhea. Gastroenterology 1989; 5: A187. 